Running head: THE MORALIZING EFFECT

\title{
The Moralizing Effect: Self-Directed Emotions and their Impact on Culpability Attributions
}

\author{
Elisabetta Sirgiovanni \\ Sapienza University of Rome \\ Joanna Smolenski \\ City University of New York \\ Ben Abelson \\ Mercy College \\ Taylor Webb \\ Princeton University
}

\begin{abstract}
Author note
Elisabetta Sirgiovanni, Department of Molecular Medicine, Museum of the History of Medicine*; Joanna Smolenski, Department of Philosophy, Graduate Center, City University of New York; Ben Abelson, Department of Humanities, Mercy College; Taylor Webb, Princeton Neuroscience Institute, Department of Psychology, Princeton University.
\end{abstract}

*Affiliation during the conduct of this research was Center for Bioethics, College of Global Public Health, New York University.

Declarations of interest: none.

Copyright. Permission for the use of the Guilt And Shame Proneness Scale in this project was granted by American Psychological Association and by the scale first author. For any request of permission to use the vignettes contained in this paper please contact Ben Abelson (babelson@mercy.edu).

Correspondence concerning this article should be addressed to Elisabetta Sirgiovanni, Department of Molecular Medicine, Museum of the History of Medicine, Sapienza University, Viale dell'Università 34/a 00185 Rome, Italy. Email: elisabetta.sirgiovanni@uniroma1.it.

Data set and R scripts are available at this link: https://figshare.com/s/22f87fleabc918559479 For info on data set and R scripts: Taylor Webb, taylor.w.webb@gmail.com

Acknowledgements. The authors are very thankful to Jesse Prinz and his Experimental Philosophy Lab at the City University of New York, Graduate Center, for sponsoring, supervising and providing the most helpful feedback to this work. Sirgiovanni wishes also to thank S. Matthew Liao, the NYU Center for Bioethics, and the U.S.-Italy Fulbright Research Scholar Program for supporting this research, as well as the Short-Term Mobility Program of the National Research Council of Italy and Cinzia Caporale for encouraging the very early stages of this work. 


\begin{abstract}
A general trend in the psychological literature suggests that guilt contributes to morality more than shame does. Unlike shame-prone individuals, guilt-prone individuals internalize the causality of negative events, attribute responsibility in the first person, and engage in responsible behavior. However, it is not known how guilt- and shame-proneness interact with the attribution of responsibility to others. In two Web-based experiments participants reported their attributions of moral culpability (i.e., responsibility, causality, punishment and decision-making) about morally ambiguous acts of killing in different conditions. In Study 1 the vignettes were presented in the 1st person, while in Study 2 in the 3rd person. To test proneness to guilt and shame, we utilized the GASP scale, which differentiates between the affective and behavioral components of each emotion. We found that guilt- and shame-proneness contributed to the severity of attributions in both the first and the third person, but the effect was strong only in the guilt case (both subtypes) and shame-affect case, and not in the shame-behavior case. We name this the Moralizing Effect. We wonder whether attributing a high degree of culpability to others is so obviously the path most consistent with morality. This echoes views expressed by Friedrich Nietzsche.
\end{abstract}

Keywords: guilt, shame, self-directed emotion, responsibility, morality, judgment 


\section{Introduction}

Psychological research on moral judgment has recently renewed interest in complex, selfdirected emotions (e.g., guilt and shame). These two emotions had been neglected for a couple of decades (Prinz, 2011). In fact, after some seminal research in the 1990s (see Tangney \& Dearing, 2002 for a review), moral psychology had focused mainly on basic, other-directed emotions (e.g., disgust, anger, and contempt, see Rozin et al., 1999: Haidt, 2003; Wheatly \& Haidt, 2005; Schnall et al., 2008; Pizzarro, Inbar, \& Helion, 2011; Seidel \& Prinz, 2013). Guilt and shame are both negative, painful emotions one experiences when transgressing against some moral rule (Tangney et al., 2007). They have been shown to co-occur and laypeople tend to not consistently distinguish between the two terms (Tangney \& Dearing, 2002, Ch. 2). However, psychology (Keltner \& Buswell, 1996; Tangney et al., 1996) and neuroscience (Michl et al., 2014; Bastin et al., 2016) have provided evidence that they are distinct emotions. Accordingly, some theoretical distinctions between guilt and shame have been adopted in empirical research. These include the idea that guilt is directed toward behavior while shame is toward the self (Lewis, 1971), and that guilt occurs when one's moral infractions remain private, while shame is caused by public display of one's transgressions (Benedict, 1946). The two emotions have also been associated with characteristic behavioral responses: reparative behavior for guilt and avoidant behavior for shame, respectively (Cohen et al., 2011). Excessive guilt and shame are also included as symptoms of many psychiatric conditions (e.g., depression, hypomaniac episodes, post-traumatic stress disorder, dissociative disorders, eating disorders, sexual dysfunction, borderline personality disorder, and paraphilic disorder for guilt; obsessive-compulsive disorder, PTSD, dissociative disorders, eating disorders, borderline, avoidant disorder, and anxiety for shame) (APA, 2013), while individuals with 
antisocial traits have been shown to lack these two emotions (Hare, 1998), especially guilt. Nevertheless, guilt and shame are not always distinguished consistently in the DSM (see Fontenelle, de Oliveira-Sousa, Moll, 2015).

Indeed, there is a general trend in the psychological literature suggesting that guilt contributes to morality more than shame does. Remarkably, there are divergent meanings of what "being moral" might denote, for instance either acting in a certain way (i.e. being a moral agent) or distinguishing right from wrong (i.e. being a moral judge) - and it is not so obvious that one sense should entail the other as traditional moral philosophers believed (Cova, 2013). In this area of research about guilt and shame, morality has been intended mostly in agentive rather than reflective terms, i.e. in this context morality has meant pro-sociality. In June Tangney and collaborators' words, "empirical results converge, indicating that guilt but not shame is most effective in motivating people to choose the moral paths in life" (Tangney et al., 2007, p. 10). The narrative of guilt being more moral than shame has developed largely due to research on the relationship between guilt/shame and behavioral intentions concerning hypothetical scenarios (i.e., participants responded to questions like "how would you behave in such situation?"), and less often explicitly on the relationship between guilt/shame and moral judgments of the rightness/wrongness of actions (for an overview, Tangney \& Dearing, 2002; see also Cohen et al., 2012). In support of the claim about the agentive morality of guilt vs. shame, Tangney (1994) found evidence of a positive correlation between self-reported moral behavior with guilt, but not with shame. Guilt in general seems to enhance one's sense of self-control and risky judgments (Kouchaki et al., 2014) and positively correlates with forgiveness-seeking, but only in the absence of shame (Riek et al., 2014). Moreover, high guilt-prone individuals engage in counterproductive work behavior less frequently (Cohen et al., 2012; Cohen et al., 2013), have better leadership skills (Schaumberg \& 
Flynn, 2012), and are more likely to be interpersonally trustworthy at the workplace (Levine et al., 2018), than low guilt-prone individuals. By contrast, shame, but not guilt, has been linked to anger and self-reported aggression (Tangney et al., 1992), as well as criminal behavior and recidivism (Tangney et al., 2011, Tangney et al., 2014). It must be noted, however, that in most of these experiments, actions were self-reported and not performed in reality.

Speculative attempts at characterizing potentially harmful aspects of guilt were engaged in by the philosopher Friedrich Nietzsche in his second essay of On the Genealogy of Morality (1887), “'Guilt', 'bad conscience' and related matters". Nietzsche thought that guilt, being an inward cruelty, turned into a bad conscience, which is potentially a result of the internalization of outward moralization (particularly, that associated with Christian tradition) created by ressentiment towards others, an attitude that he views negatively. In his own words, "it is easy to guess who has the invention of 'bad conscience' on his conscience, - the man of ressentiment!" (Nietzsche, 1887/2007, p. 49, original italics; for a discussion see Elgat, 2017). These ideas, elaborated by Freudian psychoanalysis (e.g., Freud, 1923; see also Piers and Singer, 1953; on Nietzsche and Freud see Greer, 2002), have been discarded by empirical psychology as they were thought to conflate guilt and shame, thereby mislabeling shame experiences as guilt experiences (Lewis, 1971; Tangney \& Dearing, 2002). Although some traces of these ideas remain in clinical psychopathology (Mancini \& Mancini, 2015; Mancini \& Gangemi, 2016; see also Carni et al., 2013 for an overview), some recent experiments have questioned the morality of guilt (de Hooge et al., 2011) and a few authors have speculated in defense of shame (Deonna et al., 2012), the general narrative that shame, but not guilt, can be deleterious is deep-rooted in psychology and philosophy (see Nussbaum, 2009). 
Moreover, one might suppose that divergent moral outcomes result from the link, presumed by Nietzsche scholars and Freudians, between guilt/shame and different religious traditions, or from the link between these emotions and different cultures, as proposed by some anthropologists (Benedict, 1946). These ideas have inspired only a few, inconclusive, empirical studies (e.g., Hutchinson et al., 1998; Walinga et al. 2005; Vaisey et al., 2008; see also Tangney and Dearing, 2002: 152-153).

However, guilt and shame are not only significant for their contribution to pro- or antisocial behaviors. Experts in the field tend to agree that when these emotions are present, "some degree of moral judgment would seem to be indirectly involved" (Tangney \& Dearing, 2002, p. 43) and that "one has internalised moral values" (Cohen et al., 2012, p. 355). In the debate about guilt and shame, these emotions are considered "'self-conscious emotions' that are evoked by selfreflection and self-evaluation" (Tangney \& Tracy, 2013), whether "implicit or explicit, consciously experienced or transpiring beyond our awareness", directed alternatively toward the behavior or toward the self (see also Cohen et al., 2011). Although moral judgment is not necessarily indicative of moral action (Cova, 2013), our research was driven by the idea that it is worthwhile to understand the moral judgments that guilt/shame prone individuals do, so as to better characterize the connection between these emotions, beliefs and the kind of actions they motivate. Indeed, this assessment of the "antecedents" of moral behavior may be a first step in addressing a question about morality that has been taken to be relevant to past empirical research on moral emotions in general (Ellemers et al., 2019).

In order to be morally accountable, an agent need not possess a sophisticated knowledge of her moral reasons (i.e., so-called deliberative agency, see Levy \& Bayne, 2004), but at least she has to recognize the conditions under which one, including herself, might be held responsible or 
punished for some transgressions. This is a minimal solution to problems such as automatism or involuntary conduct, which has been suggested in the legal domain (Yannoulidis, 2012), and is easily applicable to morality. It must also be noted that the idea of equating morality with mere pro-sociality is contested by influential moral philosophers. For example, according to John Harris, morality is conceived as "basically a matter of choosing what is for the best all things considered, not simply being well motivated or pro-social; in short that to be good is not simply happening to do no evil but choosing for a reason, choosing on the basis of evidence and argument, not to do wrong" (Harris 2016a, p. 270; see also Harris, 2016b). This position contests the view defended by some neuropsychologists that emotional interventions aimed at increasing pro-sociality, bypassing cognition, would be sufficient to enhance someone's moral behavior.

Additionally, guilt and shame are intimately related to the notion of responsibility - indeed, 'guilty' and 'responsible' are often used as synonyms in ordinary language. Given that responsibility attributions are a significant metric for investigating people's moral beliefs (Nichols and Knobe, 2007), investigating this relationship can give us insight into the moral beliefs of guiltand shame-prone individuals and contribute to the analysis of the morality of these emotions. Thus far, attributions of responsibility have only been tested in the context of guilt and shame in the first-person dimension (Riek et al., 2014; Tangney, 1990; Tangney et al., 1996). The links with attributional styles (in terms of causality and blame) have also been addressed, but only when the scenarios were presented in the first person. It was found that guilt tends to result in the internalization of cause or blame for negative events (self-blame), while shame results in their externalization (Tangney, 1990; Tangney et al., 1992). The relation between guilt/shame and responsibility attributions in the third-person dimension, the existence of which seems less obvious than in the first-person, has not been explicitly investigated. Specifically, although it is known that 
guilt-prone individuals make severe attributions of responsibility to themselves, we do not know whether they will also make such severe judgments about others. A large body of previous work has highlighted asymmetries between first and third person judgements, such as the actor-observer asymmetry (Jones \& Nisbett, 1971), the self-serving bias (Miller \& Ross 1975), or the fundamental attribution error (Ross, 1977), all evidencing more benevolent judgments in the first person than in the third. However, it is not known whether and how these asymmetries will interact with guiltand shame-proneness.

Another open question concerns the distinct factors that contribute to responsibility attributions in folk ethics. People usually believe, to hold someone responsible for an action, the someone in question must have caused the outcomes of an action (causality), decided intentionally to act that way (decision-making), and be consistently punishable for that action (punishment) (Fischer and Ravizza, 1998). These other dimensions, relevant to responsibility, are different, separate components that contribute to responsibility attributions in degrees and have not been investigated together by previous studies. Among the three, punishment attributions concern a selfreported action to be taken in the future (i.e., to punish or not), so they are related on agentive morality exactly as most previous literature on guilt/shame investigates. Thus, considering punishment alongside with other antecedent conditions (causality, decision-making) may suggest an interesting relationship between guilt/shame and moral action/judgment.

We must note that, even in folk ethics, there are apparently exceptions to the presence of causality (i.e., omissions) and decision-making (i.e., negligence) for responsibility attributions. However, it seems that even in these exceptional cases causality and decision-making are somehow present and relevant. In omissions, one just performs a different action from the action 
one should perform as prescribed by social norms, while in negligence one still decides and intends to act in a certain way even if the one ignores somehow the consequences of that action.

To this end, the objective of our study was to see whether and how guilt and shame impact responsibility attributions in all their specific dimensions that precede and follow the action, including causality, decision-making, and punishment. Moral culpability (Moore, 1996) seems to be the concept that properly brings together responsibility, causality, decision-making, and punishment, in the guilt dimension, given that culpa is the Latin word for guilt.

We tested the severity of culpability attributions both in the first- and third-person for individuals who are prone to guilt or shame. Apart from examining the first/third person dimension, we also explored the impact of: (a) different types of interconnected attributions, all related to the broader concept of moral culpability (i.e., responsibility, causality, decision-making, and punishment) (see for example Hitchcock \& Knobe, 2009 for the link between norms and causality); (b) the introduction of mitigating conditions (such as coercion) and (c) affective and behavioral components of guilt and shame, using a recently introduced trait assessment, the GASP scale (Cohen et al., 2011) that differentiates between these subcomponents.

We hypothesized that culpability attributions would be more severe in guilt-prone individuals than in shame-prone individuals. In the psychological literature, amplifying the moral significance of violations when making moral judgments has been named moralizing (Rozin, 1999; Horberg et al., 2009, 2011). Consistent with this literature, we refer to severe culpability attributions as moralizing. We also hypothesized that, consistently with the attributional style patterns found for guilt and shame by previous studies (Tangney, 1990; Tangney et al., 1992), showing that guilt internalizes causality and blame of actions while shame externalizes them, the effect would be more pronounced in the first-person dimension than in the third for guilt-prone 
individuals (self-critical moralizing, or a form of internalization of the blaming). Alternatively, we expected more severity in the third-person than in the first for shame-prone individuals (othercritical moralizing, or a form of externalization of the blaming).

\section{Materials and Methods}

We performed two Internet-based experiments to test whether proneness to guilt and/or shame affects culpability attributions. The research, including its materials and methods, was approved by the Institutional Review Board at the City University of New York. Formal permission for using the Guilt and Shame Proneness Scale (Cohen et al., 2011) was provided by the American Psychological Association and by the first author of the scale.

The two surveys, composed of 5 sections totaling 27 questions, were designed through the SurveyMonkey platform. English-speaking participants were recruited through Amazon Mechanical Turk. MTurk has been shown to be a reliable source for getting high-quality and representative data, especially within the United States, and is also an especially diverse subject pool (Mason and Suri, 2012).

All participants expressed written informed consent at the beginning of each survey (Section 1, Q1). After being assigned a code, they were compensated with a small sum (0.50 USD) for their participation at the end of the survey.

We collected a sample of online participants in both studies 1 and 2. The number of participants who completed the survey in Study 1 were $N=101$, including 48 women, 52 men and 1 subject who didn't identify with either category. Participants' ages ranged from 19 to 69 years old $(M=35.48)$. A hundred participants were from the United States, and only one was from elsewhere. 
In Study 2, $N=116$ participants completed the survey, including 56 women, 57 men, and 3 individuals who didn't identify with either of these categories. Participants' ages ranged from 18 to 75 years old $(M=35.4)$, and all participants were from the U.S.. Information regarding the ethnicity and religious affiliation of all participants in both studies can be found in Table 1.

To test attributions of moral culpability, we designed 4 different vignettes, each of which described the same morally ambiguous act of killing under different conditions. These vignettes were presented randomly to participants in Section 2 (Q2-5) just after expressing informed consent. In each of the 4 scenarios, the agent finds a stranger at home and fatally stabs and kills this intruder. Three of the vignettes include a different potentially mitigating circumstance (i.e., intoxication, coercion, and false information), and the 4th, a control vignette, had no such circumstance (see Table 2). Due to the conceptual vagueness of the term 'responsibility,' we decided not to ask only for explicit responsibility attributions, but also for other kinds of attributions often conceptually connected to the notion of responsibility, all belonging to the broader concept of moral culpability (see Fischer \& Ravizza, 1998). The 4 questions (i.e., about responsibility, causality, decision-making, and punishment) are listed in Table 3. The participants indicated their responses on a 7 point Likert-type scale (from $1=$ not at all, to $7=$ strongly).

In Study 1, the agent in the vignettes was presented in the 2nd person ("you"), asking the participant to put him/herself in the scenario in order to obtain $1^{\text {st }}$ person attributions. In Study 2, the agent, for whom we chose the gender-neutral name "Sam", was presented in the $3^{\text {rd }}$ person.

To test for individual proneness to guilt and shame, we used all 16 items of the Guilt and Shame Proneness Scale (GASP) (Cohen et al., 2011). The GASP scale was built and validated in continuity with previous scales (e.g., TOSCA-3, Tangney, et al., 2000). However, we decided to use the GASP scale because, unlike the TOSCA, the GASP differentiates between the affective 
and behavioral components of each emotion, resulting in 4 subscales. Specifically, the GASP scale contains 4 items for guilt-negative behavior evaluation (Guilt-NBE), 4 items for guilt-repair (GuiltR), 4 items for shame-negative self-evaluation (Shame-NSE) and 4 items for shame-withdraw (Shame-W). Guilt-NBE items are meant to capture a person's proneness to bad feelings about her actions, while Guilt-R items are concerned with one's proneness to intend to compensate for her actions. Meanwhile, Shame-NSE items address a person's proneness to feeling bad about herself after a transgression, while Shame-W has to do with proneness to intend to hide or withdraw. Our choice to keep the affective and behavioral components of guilt and shame distinct was motivated by an interest in whether or not the components differentially affect responsibility attributions. To this end, we decided to look at trait emotions rather than induced emotions since the induction of guilt and shame separately, especially the induction of their specific subtypes, would be very difficult and would imply a choice among different kinds of inductions (McLatchie et al., 2016).

In the GASP, participants are asked to answer questions about their likelihood, on a 7 point Likert-type scale from 1 (=unlikely) to 7 (=very likely), to feel or act in a particular way, which is intended to measure their possession of characteristics corresponding to the 4 subscales (examples of the GASP items are in Table 4).

We tested participants using the GASP scale (Section 3, Q6-Q21) after asking them the four types of attribution questions in response to the moral vignettes (Q2-5), in order to avoid any possible influence of the GASP items. We used a 7 point Likert-type scale for attributions to be consistent with the range of responses to the GASP items.

Demographic questions (Section 4, Q22-Q27) were posed at the end, asking for gender, ethnic/racial background, country of residence, current religion, childhood religion, and age. Internal randomization was utilized in all 3 sections. 
Statistical analyses were performed in Matlab, and R.

Table 1. Demographic information for all participants in Study $1(N=101)$ and Study $2(N=$ 116). A. Ethnic and racial background. B. Religious affiliation (RA - childhood and current).

A.

\begin{tabular}{|l|l|l|}
\hline & Study 1 & Study 2 \\
\hline African American, Black & 10 & 11 \\
\hline Chinese & 3 & 2 \\
\hline Indian & 2 & 2 \\
\hline Japanese & 0 & 1 \\
\hline Korean & 3 & 1 \\
\hline Southeast Asian & 1 & 1 \\
\hline White Caucasian - Non Hispanic & 50 & 63 \\
\hline Hispanic or Latino & 7 & 3 \\
\hline Mexican & 1 & 1 \\
\hline American Indian, Alaskan Native & 0 & 0 \\
\hline Middle Eastern & 1 & 0 \\
\hline European, White & 19 & 24 \\
\hline More than one race & 1 & 3 \\
\hline Not reported or listed & 1 & 2 \\
\hline Decline to answer & 2 & 2 \\
\hline & 0 & 24 \\
\hline
\end{tabular}


B.

\begin{tabular}{|l|l|l|l|l|}
\hline & $\begin{array}{l}\text { Study 1 } \\
\text { (RA - } \\
\text { childhood) }\end{array}$ & $\begin{array}{l}\text { Study 1 } \\
\text { (RA - } \\
\text { current) }\end{array}$ & $\begin{array}{l}\text { Study 2 } \\
\text { (RA - } \\
\text { childhood) }\end{array}$ & $\begin{array}{l}\text { Study 2 } \\
\text { (RA - } \\
\text { current })\end{array}$ \\
\hline Protestant & 24 & 17 & 40 & 25 \\
\hline Orthodox & 1 & 2 & 4 & 3 \\
\hline Catholic & 37 & 22 & 27 & 18 \\
\hline Islamic & 2 & 3 & 1 & 0 \\
\hline Jewish & 2 & 2 & 2 & 3 \\
\hline Buddhist & 0 & 1 & 1 & 2 \\
\hline Hindu & 0 & 0 & 1 & 1 \\
\hline Confucian & 0 & 0 & 0 & 0 \\
\hline Yes (religious), not listed & 10 & 13 & 11 & 14 \\
\hline None (Atheist, Agnostic, etc.) & 23 & 39 & 26 & 44 \\
\hline Decline to answer & 2 & 2 & 3 & 6 \\
\hline
\end{tabular}

Table 2-3. Moral vignettes in different conditions (blank, intoxication, coercion, false information) and kinds of questions (responsibility, causality, punishment, decision-making) for $1^{\text {st }} / 3^{\text {rd }}$ person version.

\footnotetext{
Blank condition

$1^{\text {st }} / 3^{\text {rd }}$ person version

You (Sam) come(s) home at night to find(s) a stranger standing in your living room. You (Sam) see(s) a sharp kitchen knife on the counter, pick(s) it up and fatally stab(s) the stranger in the chest.

\section{Intoxication condition}

$1^{\text {st } /} 3^{\text {rd }}$ person version

You (Sam) come(s) home at night intoxicated from an evening of heavy drinking and find(s) a stranger standing in your living room. You (Sam) see(s) a sharp kitchen knife on the counter, drunkenly pick(s) it up and fatally stab(s) the stranger in the chest.
} 


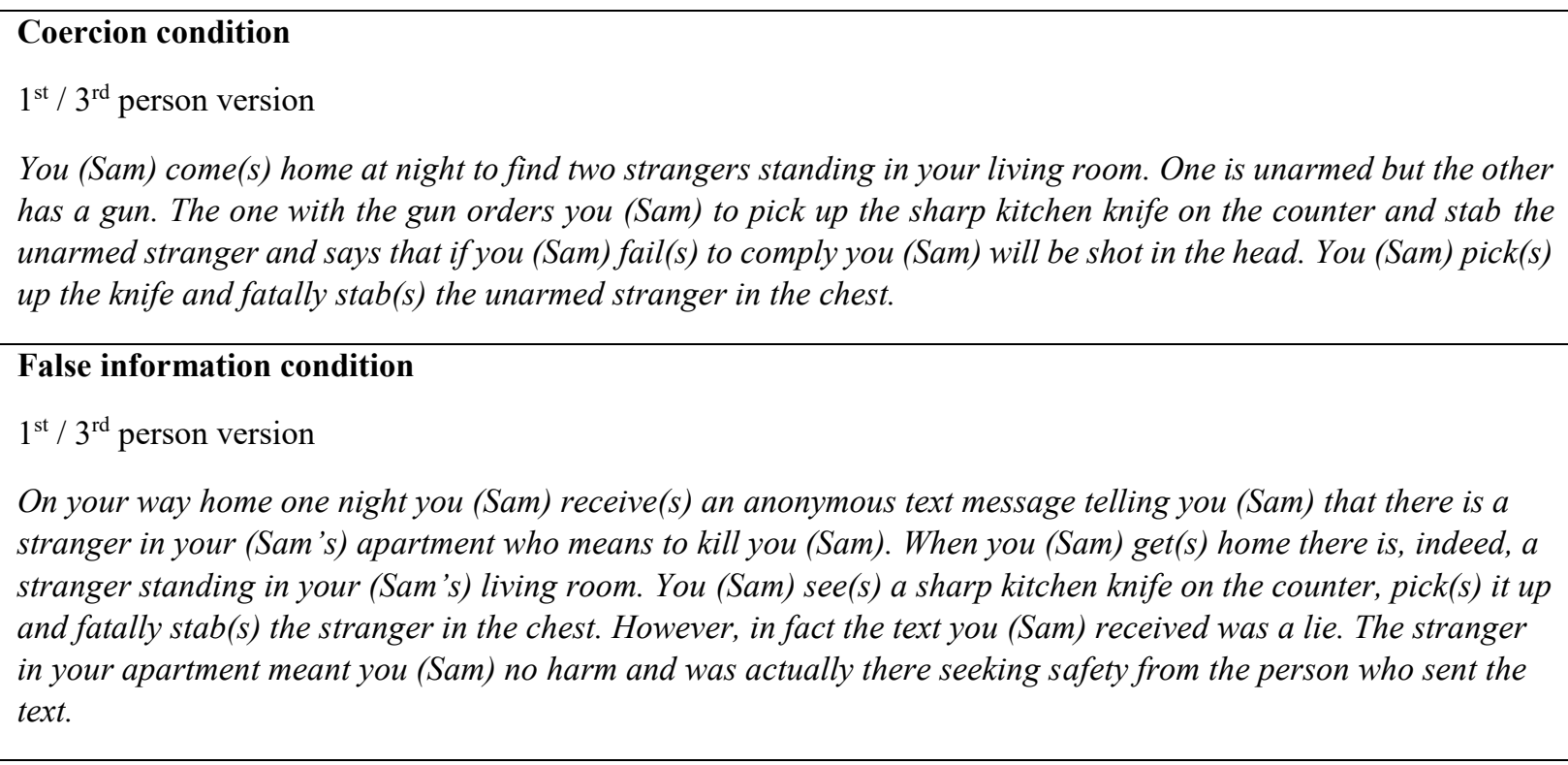

\begin{tabular}{|l|}
\hline Questions for $\mathbf{1}^{\text {st }} / \mathbf{3}^{\text {rd }}$ person version \\
\hline - How responsible are you (is Sam) for performing this action? \\
(responsibility question) \\
- How much did you (Sam) cause this outcome? \\
(causality question) \\
- How much should you (Sam) be punished? \\
(punishment question) \\
- Did you (Sam) decide to perform this action? \\
(decision-making question) \\
\hline
\end{tabular}

Table 4. Four sample items of the GASP scale (Cohen et al. 2011), one for each subscale.

\begin{tabular}{|l|l|}
\hline Guilt-NBE & $\begin{array}{l}\text { After realizing you have received too much change at a store, you decide to keep it because the } \\
\text { salesclerk doesn't notice. What is the likelihood that you would feel uncomfortable about } \\
\text { keeping the money? }\end{array}$ \\
\hline Guilt-repair & $\begin{array}{l}\text { You reveal a friend's secret, though your friend never finds out. What is the likelihood that your } \\
\text { failure to keep the secret would lead you to exert extra effort to keep secrets in the future? }\end{array}$ \\
\hline Shame-NSE & $\begin{array}{l}\text { You rip an article out of a journal in the library and take it with you. Your teacher discovers } \\
\text { what you did and tells the librarian and your entire class. What is the likelihood that this would } \\
\text { make you would feel like a bad person? }\end{array}$ \\
\hline
\end{tabular}




\begin{tabular}{|l|l|}
\hline $\begin{array}{l}\text { Shame- } \\
\text { withdraw }\end{array}$ & $\begin{array}{l}\text { After making a big mistake on an important project at work in which people were depending on } \\
\text { you, your boss criticizes you in front of your coworkers. What is the likelihood that you would } \\
\text { feign sickness and leave work? }\end{array}$ \\
\hline
\end{tabular}

\section{Results}

We first examined the extent to which moral culpability, characterized by the 4 types of attributions (responsibility, causality, punishment, and decision-making), is predicted by scores on the GASP's 4 subscales for guilt and shame (descriptive statistics for these variables are presented in Table 5).

Table 5. A. Descriptive statistics for all independent variables (GASP subscales). $\alpha$ indicates the internal reliability of each subscale. B. Descriptive statistics for all dependent variables.

A.

\begin{tabular}{|l|l|l|l|l|}
\hline & Mean & St. Dev. & Range & $\alpha$ \\
\hline Guilt-NBE & 5.30 & 1.35 & $1-7$ & 0.81 \\
\hline Guilt-Repair & 5.49 & 1.10 & $1-7$ & 0.73 \\
\hline Shame-NSE & 5.37 & 1.27 & $1-7$ & 0.78 \\
\hline Shame-Withdraw & 3.49 & 1.28 & $1-7$ & 0.65 \\
\hline
\end{tabular}

B.

\begin{tabular}{|l|l|l|l|}
\hline & Mean & St. Dev. & Range \\
\hline Responsible & 4.93 & 1.36 & $1-7$ \\
\hline Causal & 4.71 & 1.38 & $1-7$ \\
\hline Punish & 3.81 & 1.48 & $1-7$ \\
\hline Decision & 5.16 & 1.37 & $1-7$ \\
\hline
\end{tabular}


To do this, we produced a single attribution score for each participant by taking the average of all attributions made by that participant. We then performed 4 separate linear regressions, each examining the predictive capacity of 1 subscale. We followed the GASP authors' recommendation to perform separate regression analyses in order to avoid possible multicollinearity problems and to retain any shared variance between guilt and shame that might be excluded by creating the artificial constructs of guilt-free shame and shame-free guilt (Cohen et al., 2011, p. 955). We did so as we concurred with the GASP authors in their skepticism about the "utility of such computations given that, phenomenologically, people are unlikely to experience guilt without a hint of shame or shame without a tinge of guilt" (Cohen et al., 2011, p. 951). This decision is justified statistically by the fact that guilt and shame are shown to typically co-occur (Paulhus, Robins, Trzeesniewski, \& Tracy, 2004).

Because 4 separate regressions were performed, we performed Bonferroni corrections for 4 comparisons. The results revealed that attributions were significantly predicted by the subscales for both the affective dimension of guilt (Figure 1A, $\beta=0.28, p<0.0001$, Bonferroni corrected for 4 comparisons) and the behavioral dimension of guilt (Figure $1 \mathrm{~B}, \beta=0.34, p<0.0001$, Bonferroni corrected for 4 comparisons), but only the affective dimension of shame (Figure 1C, $\beta$ $=0.24, p<0.001$, Bonferroni corrected for 4 comparisons). The subscale for the behavioral dimension of shame did not significantly predict attributions of any type (Figure 1D, $\beta=-0.01, p$ $=0.81$, uncorrected). Interestingly, this result mirrors the covariance structure reported by the scale authors, whereby the affective subscale for shame (Shame-NSE) shared more variance with the guilt subscales (i.e., Guilt-NBE and Guilt-R) than it did with the behavioral subscale for shame (Shame-W) (Ibid., p. 950). These results are consistent with our moralizing effect hypothesis for both dimensions of guilt and the affective dimension of shame, but not the behavioral one. 
A

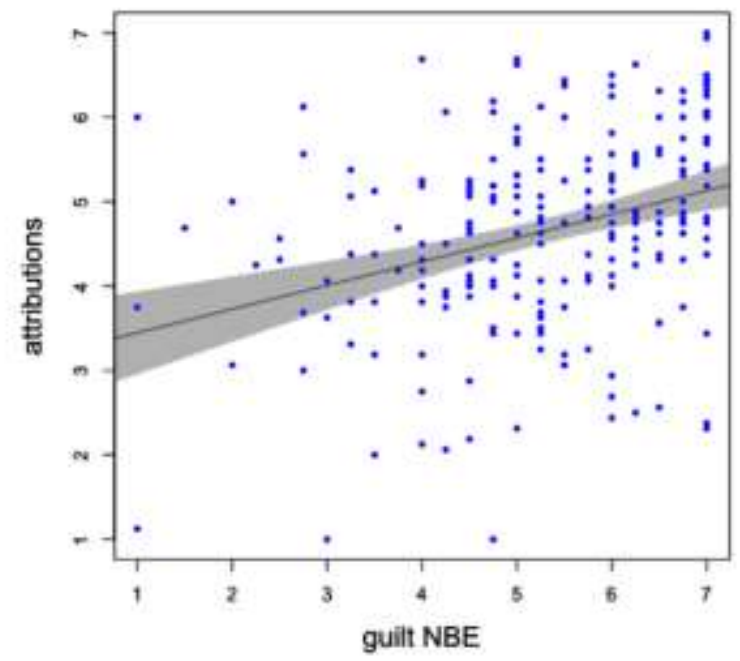

C

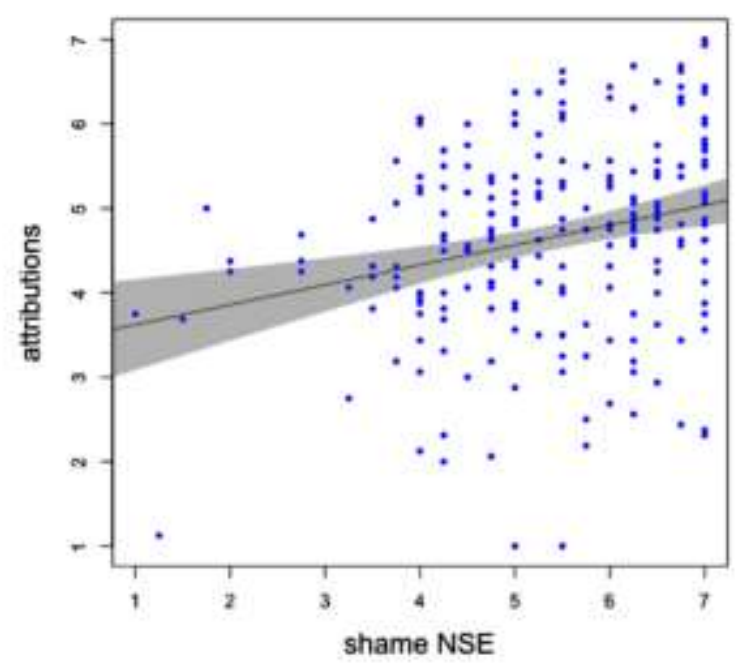

B

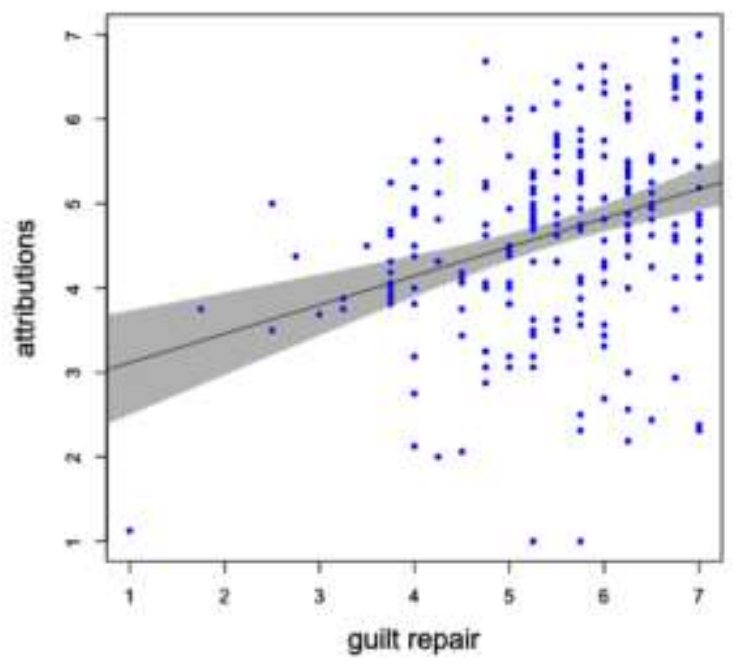

D

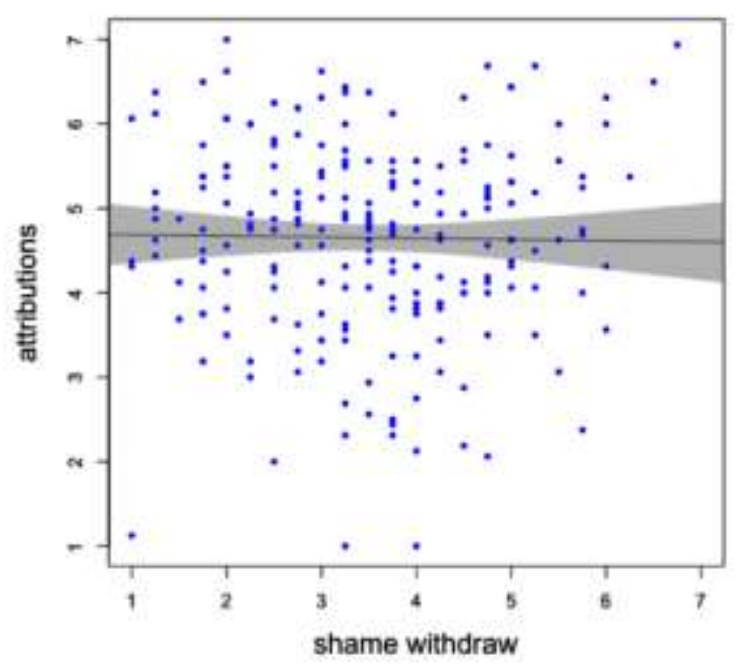

Figure 1. Regression models for the relationship between culpability attributions and subscales for guilt and shame. Shaded gray area represents $95 \%$ confidence intervals. A. Affective subscale for guilt (Guilt-NBE). B. Behavioral subscale for guilt (Guilt-R). C. Affective subscale for shame (Shame-NSE). D. Behavioral subscale for shame (Shame-W). 
We next examined whether this pattern was different when participants were making 1st vs. 3rd person attributions. We performed 8 separate regressions, assessing the extent to which the 4 subscales predicted attributions separately in the 1 st and 3 rd person conditions. We did not find any evidence to support our hypotheses regarding differences between 1st and 3rd person attributions, and, indeed, the pattern looked remarkably similar in these two conditions. In the 1stperson condition, attributions were significantly predicted by both the affective (Guilt-NBE, $\beta=$ 0.26, $p<0.05$, Bonferroni corrected for 8 comparisons) and behavioral (Guilt-R, $\beta=0.41, p<$ 0.01, Bonferroni corrected for 8 comparisons) dimensions of guilt, and by the affective dimension of shame (Shame-NSE, $\beta=0.33, p<0.05$, Bonferroni corrected for 8 comparisons), but not the behavioral dimension of shame (Shame-W, $\beta=-0.1, p=0.36$, uncorrected). In the 3rd-person condition, attributions were significantly predicted by both the affective (Guilt-NBE, $\beta=0.3, p<$ 0.001, Bonferroni corrected for 8 comparisons) and behavioral (Guilt- $\mathrm{R}, \beta=0.3, p<0.01$, Bonferroni corrected for 8 comparisons) dimensions of guilt. The results were marginally significant for the affective dimension of shame, but did not pass Bonferroni corrections (ShameNSE, $\beta=0.18, p=0.0125$, uncorrected), and were not significant for the behavioral dimension of shame (Shame-W, $\beta=0.05, p=0.46$, uncorrected). We also looked for interactions between the 4 subscales and the 1 st vs. 3rd person dimension. Each regression included the one dependent variable, our average measure of culpability attributions, and three independent variables: 1) 1 of the 4 subscales for guilt and shame, 2) whether the moral attributions in question were 1st or 3rd person (coded as a dichotomous, between-subjects predictor), and 3) the interaction between variables 1 and 2 . These results were Bonferroni corrected for 4 comparisons. The results revealed no significant interactions between 1st vs. 3rd person attributions and the subscales for guilt and shame, and, surprisingly, no main effect of 1st vs. 3rd person (Table 6A). To confirm this, we 
performed a t-test between 1st and 3rd person attributions, which again revealed no significant effect (two-sample t-test, $t=0.82, p=0.41$ ). In sum, we did not find any evidence to support of our hypotheses regarding ways in which guilt and shame proneness might interact with 1st vs. 3rd person attributions, and instead found a pattern that was robust across these two conditions.

Finally, we examined the effect of factors that might mitigate culpability attributions. These included circumstances in which agents acted under conditions of coercion, intoxication, or false information, as well as a control case that did not involve mitigating factors. We found the same pattern when considering only cases that included mitigating factors. Limiting the data to these cases, we found that attributions were significantly predicted by both the affective (GuiltNBE, $\beta=0.3, p<0.0001$, Bonferroni corrected for 4 comparisons) and behavioral (Guilt-R, $\beta=$ $0.33, p<0.0001$, Bonferroni corrected for 4 comparisons) dimensions of guilt, and the affective dimension of shame (Shame-NSE, $\beta=0.23, p<0.01$, Bonferroni corrected for 4 comparisons), but not the behavioral dimension of shame (Shame-W, $\beta=-0.02, p=0.76$, uncorrected). We also looked for interactions between the 4 subscales and the presence of mitigating factors. We performed 4 separate multiple regressions. The dependent variable for each regression was our average measure of culpability attributions, and the independent variables were: 1) 1 of the 4 subscales for guilt and shame, 2) whether the scenario in question involved mitigating factors (dichotomous, within-subjects predictor), and 3) the interaction between variables 1 and 2 . These results revealed no significant interactions between the subscales for guilt and shame and whether an attribution involved mitigating factors (Table 6B). Overall, these analyses showed that the primary pattern of results, that attributions are predicted by both subscales of guilt, and by the affective but not behavioral dimension of shame, was robust to the presence of potentially mitigating factors. 
Surprisingly, our analysis did not reveal a significant main effect of mitigating factors, suggesting that perhaps participants were not sensitive to these factors in making culpability attributions. To investigate further, we performed two analyses. First, we directly compared culpability attributions in cases with vs. without mitigating conditions. This analysis yielded a significant result (paired $t$-test, $t=9.56, p<0.0001$ ). This result suggests that the lack of a main effect of mitigating factors is due in part to the presence of the interaction term in the regressions in Table 6B. Without this term, the effect of mitigating factors is significant. Second, we examined each type of mitigating factor separately. We performed paired t-tests between attributions involving 1 of the 3 different kinds of potentially mitigating factors, and attributions involving no mitigating factors. Because we asked participants about scenarios involving 3 different kinds of mitigating factors, we performed Bonferroni corrections for 3 comparisons. This analysis revealed that attributions of culpability were significantly altered by scenarios involving either coercion (paired t-test, $\mathrm{t}=13.5, \mathrm{p}<0.0001$, Bonferroni corrected for 3 comparisons) or false information (paired t-test, $\mathrm{t}=3.5, \mathrm{p}<0.01$, Bonferroni corrected for 3 comparisons), but not intoxication (paired t-test, $\mathrm{t}=0.9, \mathrm{p}=0.34$, uncorrected). This result suggests that the lack of a main effect of mitigating factors (in the regressions reported in Table 6B) is due in part to the fact that participants found some mitigating factors (intoxication) less exculpating than others (coercion and false information). In sum, though we do not find any evidence for an interaction between guilt/shame and the presence of mitigating factors, our data do suggest that the presence of certain mitigating factors independently affects culpability attributions.

As for possible demographic factors (i.e., gender, childhood religion, current religion) we found only that women tend to be more Guilt-NBE prone than men (two-sample t-test, $t=3.1, p<$ 0.01, Bonferroni corrected for 4 comparisons). Given this disparity, we also tested a regression 
model that included both guilt-NBE and gender as independent variables, but only found a significant main effect of guilt-NBE (guilt-NBE, $\mathrm{p}=0.001$; gender, $\mathrm{p}=0.07$; interaction, $\mathrm{p}=0.08$ ). We also did not find any significant differences between the different kinds of attributions (responsibility, causality, decision-making, and punishment), suggesting that these different attributions reflect a single underlying concept, moral culpability. We did not find any significant effects for any of the other tested variables. 
Table 6. Regression models for interactions between the subscales for guilt and shame and different contexts of culpability attribution. $\mathrm{P}$ values are Bonferroni corrected for four comparisons, unless noted otherwise. N.S. (not significant) indicates predictors with $p>0.05$ after correction for multiple comparisons. A. Interaction with first vs. third person attributions. B. Interaction with mitigating factors.

A.

\begin{tabular}{|l|l|l|l|l|l|l|}
\hline & \multicolumn{2}{l|l}{ Subscale } & \multicolumn{2}{l|}{ First/third person } & \multicolumn{2}{l}{ Interaction } \\
\hline & B & P & B & P & B & P \\
\hline Guilt - affective & 0.26 & $<0.01$ & -0.04 & N.S. & 0.03 & N.S. \\
\hline Guilt - behavioral & 0.41 & $<0.001$ & 0.76 & N.S. & -0.11 & N.S. \\
\hline Shame - affective & 0.33 & $<0.01$ & 0.99 & N.S. & -0.15 & N.S. \\
\hline Shame - behavioral & -0.11 & N.S. & -0.43 & N.S. & 0.16 & N.S. \\
\hline
\end{tabular}

B.

\begin{tabular}{|c|c|c|c|c|c|c|}
\hline & \multicolumn{2}{|c|}{ Subscale } & \multicolumn{2}{c|}{ Mitigating factors } & \multicolumn{2}{c|}{ Interaction } \\
\hline & B & P & $\beta$ & P & B & P \\
\hline Guilt - affective & 0.25 & $<0.01$ & -0.87 & N.S. & 0.04 & N.S. \\
\hline Guilt - behavioral & 0.38 & $<0.0001$ & -0.38 & N.S. & -0.05 & N.S. \\
\hline Shame - affective & 0.26 & $<0.01$ & -0.47 & N.S. & -0.03 & N.S. \\
\hline Shame - behavioral & -0.0004 & N.S. & -0.59 & N.S. & -0.02 & N.S. \\
\hline
\end{tabular}




\section{Discussion}

The present studies contribute to the emerging literature on guilt and shame. The Moralizing Effect shows that individual proneness to guilt-affect, guilt-behavior, and shame-affect strongly predicts the severity of culpability attributions. Across the two experiments, it was demonstrated that increased proneness to guilt and affective shame (but not behavioral shame) significantly correlates with increased severity of culpability attributions of any type (i.e., responsibility, causality, decision-making, punishment). We found that this effect was robust across possible modulating factors.

Moreover, presenting experimental vignettes in the first- versus the third-person had no significant impact on attributional severity. This result is at odds with previous literature on the self-serving bias (Miller \& Ross 1975), which would predict more severe attributions about others than about oneself (Coleman 2011). Our findings also contradict previous results about guilt and shame and attributions of causality and blame (Tangney, 1990; Tangney et al., 1992), which would predict more severe attributions for guilt in the first person than for shame.

Furthermore, our results suggest that guilt- and affective shame-prone individuals are not moral hypocrites, i.e., those with a tendency to judge others more severely than themselves, as they tend to moralize in both first and third person culpability attributions. This result aligns with other studies showing that, even if moral hypocrisy is influenced by emotions, guilt is not among these emotions (Polman \& Ruttan, 2011; Du et al., 2019). Our analysis also suggests that shameaffect is not linked to moral hypocrisy.

Finally, the introduction of factors that may mitigate culpability judgments did not influence the Moralizing Effect, despite evidence that such circumstances have historically been taken to mitigate criminal culpability in the legal domain (Hart, 1968) and despite the fact that 
these factors independently affected culpability judgments in our own data. As previously mentioned, the existing literature on guilt and shame favors the idea that guilt contributes to morality (in terms of pro-sociality) more than shame, but our results indicate a more nuanced interpretation of this view is required. Following philosophers like John Harris, we suggest that investigating prosociality is not enough to understand fully the morality of an emotion. For one, we found that not just guilt but also the affective dimension of shame strongly correlate with severe moral judgments about culpability. It follows that analyses of the morality of guilt should also consider the morality of affective shame. Guilt and shame-affect both function as indicators of the extent to which one holds oneself or others culpable for moral transgressions, with moralizing increasing, given greater proneness to these emotions. So, our result may call into question the existence of a clear distinction between other-critical emotions (e.g., contempt, anger, and disgust) and self-critical emotions (e.g., guilt, shame, embarrassment) (see Haidt, 2003).

Some might argue that the moralizing effect we described is a positive sign of the morality of guilt and shame-affect prone people. This a plausible interpretation that has been suggested by previous literature so far (see Tangney et al., 2007). However, it is not clear that attributing a very high degree of culpability, especially to others (for some, this is called moral condemnation, see Cheng et al., 2013), is most consistent with "moral paths in life" as June Tangney believes. Indeed, we often speak colloquially of the vice of being too judgmental, harsh, or punitive. In other words, we tend to expect a "moral" agent to be measured, balanced or neutral when expressing judgments. If we think of guilt and shame in dimensional terms, we can infer that an excess of guilt and shameaffect produces outcomes we would not be willing to endorse if we want to be "moral".

In other research domains such as, for example, disgust studies, moralization has been understood to have a negative connotation because it leads to or amplifies attitudes that we find 
socially undesirable (e.g., social prejudice) (see Rozin, 1999; Kelly, 2011). Because shame has been coupled with disgust in this literature (e.g. Giner-Sorolla \& Espinosa, 2011; Terrizzi \& Shook, 2020), it is also seen as generating negative outcomes (see also Nussbaum, 2009), while guilt is not (Clark \& Fessler, 2015: 484 for a discussion). Without necessarily meaning that guilt and shame-affect make agents "immoral", insofar as moralizing is a tendency towards being excessively punitive or intolerant, it is plausible to believe that they may lead to outcomes that are harmful or unjust. This means that the relationship between guilt or shame-affect and moralizing might not be a desirable one. Moralism, in fact, has been identified as a negative attitude because it contributes to making people "uncharitable and unsympathetic" (Archer, 2018).

Consistent with a Nietzschean perspective, moralizing may be considered a morally contestable behavior. In Beyond Good and Evil (1886/2007), Nietzsche claimed that "Assuming that ... the oppressed, the suffering... should moralize: what would their moral valuations have in common? Probably a pessimistic suspicion towards the whole human condition would find expression, perhaps a condemnation of man together with his condition”. Instead of contributing to prosociality, for Nietzsche, moralization actually generates pernicious negative attitudes towards others.

Interestingly, proneness to shame-behavior (i.e. withdrawal), a trait that is intuitively associated with moral disentanglement or abdication of one's own ethical responsibility, did not correlate with these moralizing attitudes in the first or the third person. A tentative interpretation of this finding is that proneness to withdrawal involves a waiving of the self-directed judgment, also preventing the individual from moral severity towards the other. These considerations may provide reasons to reconsider the classification of emotions such as guilt and shame, and their 
subtypes, as either simply "prosocial" or "anti-social". Instead, each emotion may fall under both classifications concurrently, to different degrees that vary with contextual features.

\section{Limitations and future considerations}

One limitation of this study is that in the GASP scale, like in previous scales, dispositional guilt and shame are assessed by self-reported responses to imaginary experiences. We did not investigate occurrent states of guilt and shame, nor how guilt and shame impact culpability attributions when they are elicited in the moment by real situations. As such, we encourage future research that induces guilt and shame in order to study other instances in which the Moralizing Effect might occur.

We did not include blame, which is conceptually distinct from responsibility, explicitly in our attribution questions (i.e., desert of punishment, volition, and causality). This means that conclusions about blame specifically cannot be drawn from these results. However, we speculate that the Moralizing Effect could be extended to judgments of blame, and suggest including this dimension in future study.

Even if excessive guilt and shame are associated with a series of psychopathologies, we cannot make any further assumption about the relationship of the Moralizing Effect to psychopathological forms of guilt and shame. Our studies did not have the tools to test for the possible existence of psychopathological traits in our participants, nor did we establish normative criteria for a precise threshold for what counts as excessive guilt or shame.

We focused on the moralizing aspects of guilt and shame-affect, but it is also worthwhile to draw attention to the fact that proneness to withdrawal (shame-affect) did not appear to be a moralizing emotion, which is an interesting issue to explore and clarify in the future. We expected 
childhood religion or current religion to affect guilt and shame, and therefore our Moralizing Effect, but there was no significant impact. This may be because our sample was not sufficiently diverse with respect to religion, and so the sample size for each individual religion was too small for substantive analysis. For future research, we suggest recruiting larger samples from different religious faiths.

Given the relevance of the notion of responsibility in various domains, The Moralizing Effect may have important ramifications for further areas of study and public policy. Some of these include educational and organizational psychology, regarding child development and professional responsibility, respectively; psychiatry and mental health, concerning the understanding of mental disorders; and ethics, law and politics, with their respective notions of moral, legal, and social responsibility.

\section{Conclusion}

Evidence for the existence of The Moralizing Effect, which is the phenomenon that (both affective and behavioral) guilt and only affective (but not behavioral) shame increase the severity of culpability attributions of any type, is an important contribution to the psychological debate about self-directed emotions and responsibility. Contrary to the dominant narrative in psychology, which tends to favor the idea of the morality of guilt over shame, the Moralizing Effect calls into question the relationship between self-directed emotions and morality in a different way, permitting consideration of the moral/immoral character of these emotions from a dimensional perspective. The relationship we have found between moral emotions and responsibility attributions may have important ramifications for various areas of study and public policy, e.g. in educational and organizational psychology, child development, professional responsibility, 
psychiatry, mental health, and in ethics, law and politics, with their respective notions of moral, legal, and social responsibility.

\section{Data availability}

Data set and R scripts are available at this link: https://figshare.com/s/22f87fleabc918559479.

\section{References}

American Psychiatric Association (APA) (2013). Diagnostic and Statistical Manual of mental disorders (DSM-5). Washington, DC: American Psychiatric Publishing.

Archer, A. (2018). The problem with moralism. Ratio, 31(3), 342-350. doi: 10.1111/rati.12168

Benedict, R. (1946). The chrysanthemum and the sword. New York, NY: Houghton-Mifflin.

Bastin, C., Harrison, B. J., Davey, C. G., Moll, J., \& Whittle, S. (2016). Feelings of shame, embarrassment and guilt and their neural correlates: A systematic review. Neuroscience and Biobehavioral Reviews, 71, 455-471. doi: 10.1016/j.neubiorev.2016.09.019

Carnì, S., Petrocchi, N., Del Miglio, C., Mancini, F., \& Couyoumdjian, A. (2013). Intrapsychic and interpersonal guilt: a critical review of the recent literature. Cognitive Processing, 14(4), 333-46. doi: 10.1007/s10339-013-0570-4

Cheng, J. S., Ottati, V. C., \& Price, E. D. (2013). The Arousal Model of Moral Condemnation. Journal of Experimental Social Psychology, 49(6), 1012-1018. doi: 10.1016/j.jesp.2013.06.006

Clark, J. A., \& Fessler, D. M. (2015). The Role of Disgust in Norms, and of Norms in Disgust Research: Why Liberals Shouldn't be Morally Disgusted by Moral Disgust. Topoi, 34, 483-498. doi: $10.1007 / \mathrm{s} 11245-014-9240-0$ 
Cohen, T. R., Wolf, S. T., Panter, A. T., \& Insko, C. A. (2011). Introducing the GASP scale: A new measure of guilt and shame proneness. Journal of Personality and Social Psychology, 100(5), 947-966. doi: 10.1037/a0022641

Cohen, T. R., Panter, A. T., \& Turan, N. (2012). Guilt Proneness and Moral Character. Current Directions in Psychological Science, 21, 5, 355-359. doi: 10.1177/0963721412454874

Cohen, T. R., Panter, A. T., \& Turan, N. (2013). Predicting counterproductive work behavior from guilt proneness. Journal of Business Ethics, 114, 45-53. doi: 10.1007/s10551-012-1326-2

Coleman, M. D. (2011). Emotion and self-serving bias. Current Psychology, 30, 345-354. doi: 10.1007/s12144-011-9121-2.

Cova, F. (2013). Two Kinds of Moral Competence: Moral Agent, Moral Judge. In B.

Musschenga, \& A. van Harskamp (eds.). What Makes Us Moral? On the capacities and conditions for being moral. Dordrecht: Springer Netherlands, 117-130.

Deonna, J.A., Rodogno, R., \& Teroni, F. (2012). In defense of shame: Two faces of an emotion. Oxford-New York: Oxford University Press.

Du, X., Liu, N., Jia, Q., \& Wu, J. (2019). Guilt proneness moderates the after-effects of ego depletion on hypocrisy, Personality and Individual Differences 151, 109516. doi:

10.1016/j.paid.2019.109516.

de Hooge, I.E., Nelissen, R., Breugelmans, S.M., \& Zeelenberg, M. (2011). What is moral about guilt? Acting "prosocially" at the disadvantage of others. Journal of Personality and Social Psychology, 100(3), 462-73. doi: 10.1037/a0021459

Elgat, G. (2017). Nietzsche's Psychology of Ressentiment, Revenge and Justice in On the Genealogy of Morals. New York: Routledge. 
Ellemers, N., van der Toorn, J., Paunov, Y., \& van Leeuwen T. (2019). The Psychology of Morality: A Review and Analysis of Empirical Studies Published From 1940 Through 2017. Personality and Social Psychology Review, 23(4), 332-366. doi: 10.1177/1088868318811759

Fischer, J.M., \& Ravizza M. (ed.) (1998) Responsibility and Control: a Theory of Moral Responsibility. Cambridge: Cambridge University Press.

Fontenelle L. F., de Oliveira-Sousa R., \& Moll J. (2015). The rise of moral emotions in neuropsychiatry. Dialogues in Clinical Neuroscience, 17(4), 411-20.

Freud S. (1923). The Ego and the Id. Edited by P. Strachey (1990). New York-London: W.W. Norton \& Company Ltd.

Giner-Sorolla, R., \& Espinosa, P. (2011). Social Cuing of Guilt by Anger and of Shame by Disgust. Psychological Science, 22(1), 49-53. doi: 10.1177/0956797610392925

Giner-Sorolla, R., Piazza, J., \& Espinosa, P. (2011). What do the TOSCA guilt and shame scales really measure: Affect or action? Personality and Individual Differences, 51 (4), 445-450. doi:10.1016/j.paid.2011.04.010

Greer, S. (2002). Freud's 'bad conscience': The case of Nietzsche's Genealogy. Journal of the History of the Behavioral Sciences, 38(3), 303-315. doi: 10.1002/jhbs.10064

Haidt, J. (2003). The moral emotions. In R. J. Davidson, K. R. Scherer, \& H. H. Goldsmith (Eds.), Handbook of affective sciences. Oxford: Oxford University Press, 852-870.

Hare, R. D. (1998). The Hare PCL-R: Some issues concerning its use and misuse. Legal and Criminological Psychology, 3, 101-122. doi: 10.1111/j.2044-8333

Harris, J. (2016a). Moral Blindness - The Gift of the God Machine, Neuroethics 9, 269-273. doi: $10.1007 / \mathrm{s} 12152-016-9272-9$ 
Harris, J. (2016b). How to be Good. The Possibility of Moral Enhancement. Oxford: Oxford University Press.

Hart, H. L. A. (1968). Punishment and Responsibility: Essays in the Philosophy of Law. Oxford: Oxford University Press.

Hitchcock, C., \& Knobe, J. (2009). Cause and Norms. Journal of Philosophy, 11, 587-61. doi: 10.5840/jphil20091061128

Horberg, E. J., Oveis, C., Keltner, D., \& Cohen, A.B. (2009). Disgust and the moralization of purity. Journal of Personality and Social Psychology, 97(6), 963-976. doi: 10.1037/a0017423

Horberg, E. J., Oveis, C., \& Keltner, D. (2011). Emotions as moral amplifiers: An appraisal tendency to the influence of distinct emotions upon moral judgment. Emotion Review, 3, 1-8. doi: $10.1177 / 1754073911402384$

Hutchinson, G. T, Patock-Peckham, J. A., Cheong, J. W., Nagoshi, C. T. (1998). Personality predictors of religious orientation among Protestant, Catholic, and non-religious college students. Personality and Individual Differences, 24 (2), 145-151. doi:10.1016/S0191-8869(97)00164-5 Jones, E. E., \& Nisbett, R. E. (1971). The actor and the observer: Divergent perceptions of the causes of behavior. Morristown, NJ: General Learning Press.

Kelly, D. (2011). Disgust and Normative Ethics: The Irrelevance of Repugnance and Dangers of Moralization. In Yuck! The Nature and Moral Significance of Disgust. Cambridge, MA: MIT Press, 137-152.

Keltner, D., \& Buswell, B. N. (1996). Evidence for the distinctness of embarrassment, shame, and guilt: a study of recalled antecedents and facial expressions of emotion. Cognition and Emotion, 10 (2), 155-171. doi: 10.1080/026999396380312 
Kouchaki, M., Oveis, C., \& Gino, F. (2014). Guilt enhances the sense of control and drives risky judgments. Journal of Experimental Psychology, 143(6), 2103-10. doi: 10.1037/a0037932

Lewis, H. B. (1971). Shame and guilt in neurosis. New York: International Universities Press.

Levi, N., \& Bayne, T. (2004). Doing without deliberation: automatism, automaticity, and moral accountability, 16(3), 209-215. doi: 10.1080/09540260400003909

Levine, E., Bitterly T.B., Cohen T.R., \& Schweitzer M.E. (2018). Who Is Trustworthy?

Predicting Trustworthy Intentions and Behavior. Journal of Personality and Social Psychology, 115 (3), 468-494. doi: 10.1037/pspi0000136

Mancini, A., \& Mancini F. (2015). Do not play God: contrasting effects of deontological guilt and pride on decision-making. Frontiers in Psychology, 6, 1-12. doi: 10.3389/fpsyg.2015.01251

Mancini, F., \& Gangemi, A. (2015). Deontological guilt and obsessive compulsive disorder.

Journal of Behavioral Therapy and Experimental Psychiatry, 49, 157-63. doi:

10.1016/j.jbtep.2015.05.003

Mason, W., \& Suri, S. (2012). Conducting behavioral research on Amazon's Mechanical Turk. Behavior Research Methods, 44(1), 1-23. doi: 10.3758/s13428-011-0124-6

McLatchie, N., Derbyshire, S., \& Giner-Sorolla, R. (2016). "Imagined guilt" versus "recollected guilt”: Implications for fMRI. Social Cognitive and Affective Neuroscience, 11(5), 703-711. doi:10.1093/scan/nsw001

Michl, P., Meindl, T., Meister, F., Born, C., Engel, R. R., Reiser, M., \& Hennig-Fast, K. (2014). Neurobiological underpinnings of shame and guilt: a pilot fMRI study. Social Cognitive and Affective Neuroscience, 9(2), 150-7. doi: 10.1093/scan/nss114 
Miller, D. T., \& Ross, M. (1975). Self-Serving Biases in the Attribution of Causality: Fact or Fiction? Psychological Bulletin, 82(2), 213-225. doi: 10.1037/h0076486

Moore, M. S. (1996). Prima facie moral culpability. Boston University Law Review76(1 2), 319334.

Nietzsche, F. (1886/2006). Beyond Good and Evil. In Supplementary Material, Friedrich Nietzsche: On the Genealogy of Morality. (K. Ansell-Pearson, Ed., C. Diethe, Tr.) (2nd ed.). Cambridge: Cambridge University Press. doi: 10.1017/CBO9780511812026

Nietzsche, F. (1887/2006). Friedrich Nietzsche: On the Genealogy of Morality. (K. AnsellPearson, Ed., C. Diethe, Tr.) (2nd ed.). Cambridge: Cambridge University Press. doi: $10.1017 / \mathrm{CBO} 9780511812026$

Nichols, S., \& Knobe, J. (2007). Moral Responsibility and Determinism: The Cognitive Science of Folk Intuitions. Nous, 41(4), 663-685. doi: 10.1111/j.1468-0068.2007.00666.x

Nussbaum, M. C. (2009). Hiding from humanity: disgust, shame, and the law. Princeton: Princeton University Press.

Paulhus, D. L., Robins, R. W., Trzesniewski, K. H., \& Tracy, J. L. (2004). Two replicable suppressor situations in personality research. Multivariate Behavioral Research, 39, 303-328. doi:10.1207/s15327906mbr3902_7

Pizzarro D., Inbar Y., \& Helion C. (2011) On Disgust and Moral Judgment, Emotion Review 3(3), 267-268. doi: 10.1177/1754073911402394

Polman, E., \& Ruttan R. L. (2011) Effects of Anger, Guilt, and Envy on Moral Hypocrisy, Personality and Social Psychology Bulletin 38(1), 129-139 doi: 10.1177/0146167211422365 
Prinz, J. J. (2011). Sentimentalism and Self-Directed Emotions. In A. Konzelmann Ziv, K. Lehrer, \& B. Schmid (Eds.), Self-evaluation: Affective and social grounds of intentionality. Dordrecht: Springer, 135-153.

Riek, B. M., Root Luna, L. M., \& Schnabelrauch, C. A. (2014). Transgressors' guilt and shame: A longitudinal examination of forgiveness-seeking. Journal of Social and Personal Relationships, 31, 751-772. doi:10.1177/0265407513503595

Ross, L. (1977). The intuitive psychologist and his shortcomings: Distortions in the attribution process. In L. Berkowitz (Ed.), Advances in experimental social psychology. New York: Academic Press, 174-221.

Rozin, P. (1999). The process of moralization. Psychological Science, 10, 218-221. doi: $10.1177 / 0265407513503595$

Rozin, P., Haidt, J., \& McCauley, C. R. (1999). Disgust: The body and soul emotion. In T. Dalgleish \& M. J. Power (Eds.), Handbook of cognition and emotion. New York, NY: Wiley, 429-445.

Piers, G., \& Singer, A. (1953). Shame and guilt. Springfield, IL: Thomas.

Schaumberg R.L., \& Flynn F.J. (2012). Uneasy lies the head that wears the crown: The link between guilt-proneness and leadership. Journal of Personality and Social Psychology. 103 (2), 327-342.

Schnall S., Haidt J., Clore G. L., \& Jordan A. H. (2008). Disgust as Embodied Moral Judgment. Personality and Social Psychology Bulletin, 34 (8), 1096-1109. doi: 10.1177/0146167208317771

Seidel A., \& Prinz J. J. (2013). Sound morality: irritating and icky noises amplify judgments in divergent moral domains, Cognition, 127(1), 1-5. doi: 10.1016/j.cognition.2012.11.004 
Tangney, J. P. (1990). Assessing individual differences in proneness to shame and guilt:

Development of the self-conscious affect and attribution inventory. Journal of Personality and Social Psychology, 59, 102-111. doi: 10.1037/0022-3514.59.1.102

Tangney, J. P. (1994). The mixed legacy of the super-ego: Adaptive and maladaptive aspects of shame and guilt. In J.M. Mashng, R.E Bornstein (Eds.), Empirical perspectives on object relations theory. Washington, DC: American Psychological Association, 1-28.

Tangney, J. P., Dearing, R. L., Wagner, P. E., \& Gramzow, R. H. (2000). The Test of SelfConscious Affect-3 (TOSCA-3). Fairfax, VA: George Mason University.

Tangney, J. P., \& Dearing, R. L., (2002). Shame and guilt. New York: Guilford Press.

Tangney, J. P., Miller, R. S., Fhcker, L., \& Barlow, D. H. (1996). Are shame, guilt and embarrassment distinct emotions? Journal of Personality and Social Psychology, 70, 1256-1269. Doi: $10.1037 / 0022-3514.70 .6 .1256$

Tangney, J. P., Stuewig, J., \& Mashek, D. J. (2007). Moral emotions and moral behavior. Annual Review of Psychology, 58, 345-372. doi: 10.1146/annurev.psych.56.091103.070145

Tangney, J. P., \& Tracy J. L. (2013). Self-conscious emotions. In M.R. Leary, J.P. Tangney (Eds), Handbook of Self and Identity, Second Edition, New York, NY: Guilford Press.

Tangney, J. P., Wagner P., \& Gramzow, R. (1992). Proneness to Shame, Proneness to Guilt, and Psychopathology. Journal of Abnormal Psychology, 101(3), 469-478. doi: : 10.1037/0021843X.101.3.469

Tangney, J. P., Wagner, P., Fletcher, C., \& Gramzow, R. (1992). Shamed into anger? The relation of shame and guilt to anger and self-reported aggression. Journal of Personality and Social Psychology, 62, 669-675. doi: 10.1037//0022-3514.62.4.669 
Tangney J.P., Stuewig J., \& Hafez L. (2011). Shame, guilt and remorse: implications for offender populations. Journal of Forensic Psychiatry and Psychology, 22(5): 706-723. doi: $10.1080 / 14789949.2011 .617541$

Tangney J.P., Stuewig J., \& Martinez A.G. (2014). Two faces of shame: the roles of shame and guilt in predicting recidivism. Psychological Science, 25(3), 799-805.

doi: $10.1177 / 0956797613508790$

Terrizzi, J. A., \& Shook N. J. (2020). On the Origin of Shame: Does Shame Emerge From an Evolved Disease-Avoidance Architecture? Frontiers in Behavioral Neuroscience, 14, 1-19. doi: 10.3389/fnbeh.2020.00019

Vaisey, S., \& Smith, C. (2008). Catholic Guilt among U.S. Teenagers: A Research Note. Review of Religious Research, 49 (4), 415-426.

Walinga, P., Corveleyn, J., \& van Saane J. (2005). Guilt and Religion: The influence of orthodox Protestant and orthodox Catholic conceptions of guilt on guilt-experience. Archive for the Psychology of Religion / Archiv für Religionspychologie, 27(1), 113-136. doi:

$10.1163 / 008467206774355330$

Wheatley T., \& Haidt J. (2005). Hypnotic disgust makes moral judgments more severe. Psychological Science, 16(10), 780-784. doi: 10.1111/j.1467-9280.2005.01614.x Yannoulidis S. (2012). Mental State Defences in Criminal Law. Farnham: Ashgate. 